\title{
Investigação das atividades analgésica e antiinflamatória do extrato metanólico dos rizomas de Echinodorus grandiflorus
}

\author{
Rafael C. Dutra ${ }^{1}$, Carolina Z. Tavares ${ }^{1}$, Sávio O. Ferraz ${ }^{1}$, Orlando V. Sousa ${ }^{1 *}$, \\ Daniel S. Pimenta ${ }^{2}$
}

\author{
${ }^{1}$ Departamento Farmacêutico, Faculdade de Farmácia e Bioquímica, Universidade Federal de Juiz de Fora, \\ Campus Universitário, 36036-330, Juiz de Fora, MG, Brasil, \\ ${ }^{2}$ Departamento de Botânica, Instituto de Ciências Biológicas, Universidade Federal de Juiz de Fora, Campus \\ Universitário, 36036-330, Juiz de Fora, MG, Brasil
}

\begin{abstract}
RESUMO: O presente trabalho investigou as atividades analgésica e antiinflamatória do extrato metanólico de rizomas de Echinodorus grandiflorus. Para isto, foram realizados os testes de contorções abdominais induzidas por ácido acético; tempo da lambida da pata induzida por formalina; edema de pata e pleurisia induzidas por carragenina. As doses de 100, 200 e $400 \mathrm{mg} / \mathrm{kg}$ inibiram as contorções em $34,30 \%, 35,84 \%$ e $36,07 \%$, respectivamente. O tempo de lambida da primeira fase foi reduzido nas doses de $200 \mathrm{e} 400 \mathrm{mg} / \mathrm{kg}$, enquanto a segunda fase teve redução em $400 \mathrm{mg} / \mathrm{kg}$. As doses testadas diminuíram o edema, enquanto o volume do exsudato foi reduzido em $24,61 \%$ na dose de $400 \mathrm{mg} / \mathrm{kg}$. As doses de 200 e $400 \mathrm{mg} / \mathrm{kg}$ diminuíram a migração leucocitária. Os resultados indicam que o extrato de E. grandiflorus testado pode constituir alvo potencial para uso em terapias da dor e da inflamação.
\end{abstract}

Unitermos: Echinodorus grandiflorus, atividade analgésica, atividade antiinflamatória.

\begin{abstract}
Investigation of analgesic and anti-inflammatory activities of Echinodorus grandiflorus rhizomes methanol extract". The present work investigated the analgesic and antiinflammatory activities of the methanol extract of the rhizomes of Echinodorus grandiflorus. For this purpose, acetic acid writhing, paw licking induced by formalin, carrageenan-induced rat paw edema and pleurisy tests were performed. The doses of 100,200 and $400 \mathrm{mg} / \mathrm{kg}$ inhibited the contortions $34.30 \%, 35.84 \%$ and $36.07 \%$, respectively. The lick of the paw 1 st phase was reduced at the doses of 200 and $400 \mathrm{mg} / \mathrm{kg}$, while the $2 \mathrm{nd}$ phase had reduction at $400 \mathrm{mg} / \mathrm{kg}$. All doses inhibited the paw edema, while the volume of the exsudate was reduced $24.61 \%$ in the dose of 400 $\mathrm{mg} / \mathrm{kg}$. The doses of 200 and $400 \mathrm{mg} / \mathrm{kg}$ decreased the leukocytes migration. The results indicate that the methanol extract of E. grandiflorus can constitute target potential for use in therapies of the pain and inflammation.
\end{abstract}

Keywords: Echinodorus grandiflorus, analgesic activity, anti-inflammatory activity.

\section{INTRODUÇÃO}

A família Alismataceae possui 18 espécies do gênero Echinodorus no Brasil (Vieira; Lima, 1997). Entras estas, E. grandiflorus e E. macrophyllus possuem propriedades medicinais semelhantes e, popularmente, são denominadas de "chapéu de couro" (Lorenzi; Matos, 2002; Nunes et al., 2003). Em especial, E. grandiflorus é uma herbácea ou subarbusto aquático, perene, acaule e rizomatoso, sendo encontrada em mananciais aquáticos ou cultivada para fins medicinais (Lorenzi, 2000; Lorenzi; Matos, 2002).

Tradicionalmente, E. grandiflorus é empregada no tratamento das mais diversas patologias (Lorenzi; Matos, 2002). Lopes et al. (2000) demonstraram que o extrato aquoso de folhas secas de E. macrophyllus não induziu efeito genotóxico detectável, mas alertaram para o potencial tóxico em overdoses ou efeitos cumulativos em tratamentos prolongados. Extratos das folhas de $E$. grandiflorus demonstraram efeitos antiinflamatório (Brito et al., 1999), vasodilatador (Almeida et al., 2003) e hipoglicemiante (Barbosa-Filho et al., 2005).

Substâncias terpenoídicas das quais destacamse diterpenos dos tipos clerodano (Costa et al., 1999; Tanaka, 2000) e cembrano tais como equinodol (Manns; Hartman, 1993) e ácido equinóico (Tanaka et al., 1997, Tanaka, 2000) foram isoladas de E. grandiflorus. Os diterpenos equinofilinas A e B (Kobayashi et al, 2000) e equinodolidos A e B (Shigemori et al., 2002) foram identificados em E. macrophyllus.

Partindo do princípio que as folhas de $E$. grandiflorus demonstraram efeito antiinflamatório, neste trabalho foi investigado, através dos modelos de contorções abdominais induzidas por ácido acético, 


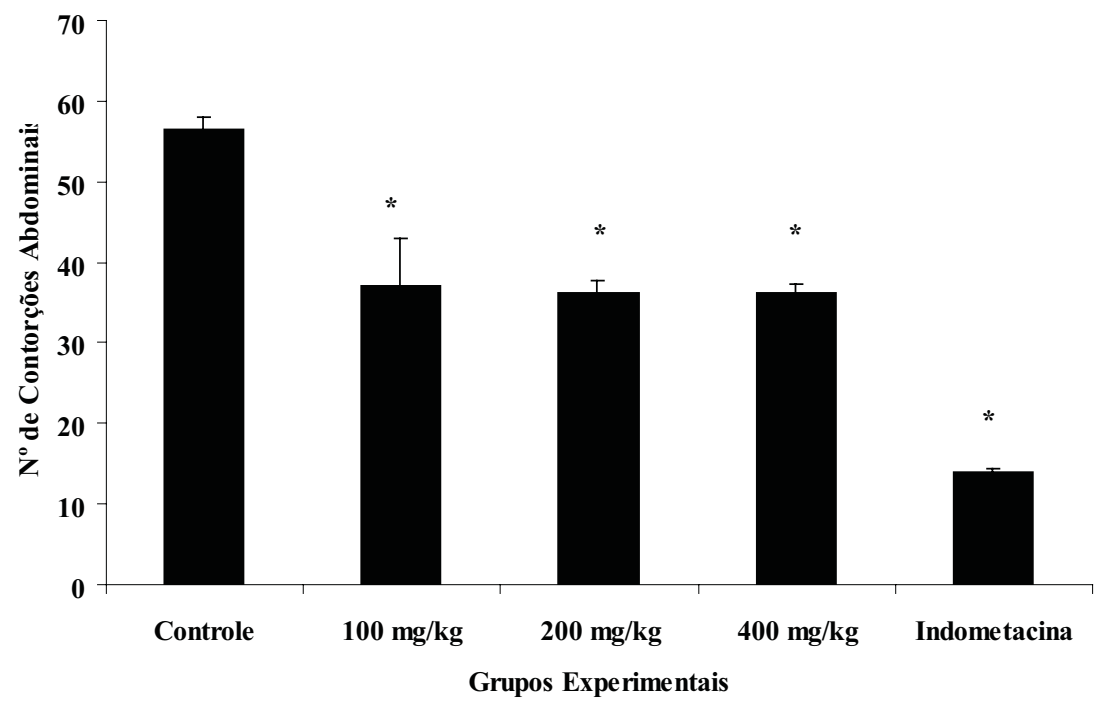

Figura 1. Efeito analgésico do extrato metanólico de Echinodorus grandiflorus sobre o número de contorções abdominais induzidos por ácido acético $(0,6 \%)$ em camundongos $(\mathrm{n}=8)$. *Significativo após análise de variância (ANOVA) seguido do teste de Student Newman-Keuls $(\mathrm{p}<0,05)$.

tempo da lambida da pata induzida por formalina, edema de pata e pleurisia induzidos por carragenina, se este efeito poderia ser atribuído também aos rizomas. Para isto, os estudos foram iniciados através da avaliação do efeito analgésico, pois são indicativos de atividade antiinflamatória.

\section{MATERIAL E MÉTODOS}

\section{Coleta do material vegetal}

Rizomas de Echinodorus grandiflorus foram coletados em novembro de 2002 em Juiz de Fora/MG em plantio sob condições de inundação intermitente. Uma exsicata da planta, identificada por Dr. Daniel Sales Pimenta, encontra-se depositada no Herbário CESJ $\left(\mathrm{n}^{\circ}\right.$ 30.707) do Departamento de Botânica da Universidade Federal de Juiz de Fora (UFJF), Juiz de Fora, Minas Gerais, Brasil.

\section{Preparo do extrato}

Após coleta, os rizomas foram submetidos à secagem em temperatura de $70^{\circ} \mathrm{C}$, com ventilação forçada, até a perda de $76 \%$ de sua umidade. O material botânico seco foi triturado em moinho mecânico com peneiras de granulação definida. Após uma prévia extração em hexano P.A. por maceração estática durante duas semanas com duas trocas de solvente, o extrato metanólico foi obtido também pelo mesmo procedimento por três semanas com cinco trocas de solvente. $\mathrm{O}$ extrato metanólico foi rotaevaporado e o resíduo seco utilizado para investigar as atividades farmacológicas.

\section{Animais}

Foram utilizados camundongos Swiss (25-30 g) machos e ratos Wistar (160-200 g) machos provenientes do Centro de Biologia da Reprodução da UFJF. Os animais foram mantidos em gaiolas plásticas com ração e água $a d$ libitum em temperatura ambiente. Doze horas antes da realização das experiências, os animais foram privados de ração. Os protocolos utilizados foram aprovados pelo Comitê de Ética na Experimentação Animal (CEEA) desta instituição (processo $\mathrm{n}^{\circ}$. 03/2006).

\section{Avaliação da atividade analgésica}

\section{Teste de contorções abdominais}

$\mathrm{O}$ teste de contorções abdominais em camundongos foi realizado de acordo com Koster et al., 1959. O extrato metanólico de E. grandiflorus foi solubilizado em dimetilsulfóxido:Tween 80 (1:1) 1\% (v/ v) em salina e administrado por via oral 1 hora antes da aplicação do ácido acético $0,6 \%$. As doses administradas foram de 100, 200 e $400 \mathrm{mg} / \mathrm{kg}$ peso de camundongo $(\mathrm{n}=$ 8 ). Uma hora após tratamento, $10 \mathrm{~mL} / \mathrm{kg}$ de ácido acético $0,6 \%$ foram administrados intraperitonealmente em cada camundongo e o $\mathrm{n}^{\circ}$ de contorções abdominais contado entre 10 e 30 minutos após este procedimento. O grupo controle recebeu $0,3 \mathrm{~mL} / 30 \mathrm{~g}$ de dimetilsulfóxido:Tween 80 (1:1) 1\% em salina por via oral (v.o.). A indometacina $(10 \mathrm{mg} / \mathrm{kg})$ foi o fármaco de referência administrado por 
via oral.

\section{Teste do tempo da lambida da pata}

O teste foi realizado de acordo com Hunskaar e Hole (1987). Camundongos foram injetados $20 \mu \mathrm{L}$ de formalina $2,5 \%$ (em salina estéril) no espaço subplantar da pata direita e a duração da lambida foi determinada de 0 a 5 minutos ( $1^{\text {a }}$ fase) e 15 a 30 minutos ( $2^{\mathrm{a}}$ fase) após aplicação da formalina. O extrato metanólico de $E$. grandiflorus foi solubilizado em dimetilsulfóxido:Tween $80(1: 1) 1 \%(\mathrm{v} / \mathrm{v})$ em salina e administrado nas doses de 100,200 e $400 \mathrm{mg} / \mathrm{kg}$, por via oral, 1 hora antes da injeção da formalina. Os animais controle receberam 10

Tabela 1. Tempo de lambida da pata induzida por formalina 2,5\% após administração de 100, 200 e $400 \mathrm{mg} / \mathrm{kg}$, por via oral, do extrato metanólico de rizomas de Echinodorus grandiflorus $(\mathrm{n}=8)$. *Significativo após análise de variância (ANOVA) seguido do teste de Student Newman-Keuls $(\mathrm{p}<0,05)$.

\begin{tabular}{lccccc}
\hline Grupos & Dose & \multicolumn{2}{c}{$1^{\mathrm{a}}$ Fase (s) (neurogênica) } & \multicolumn{2}{c}{$2^{\mathrm{a}}$ Fase (s) (inflamatória) } \\
\cline { 3 - 6 } experimentais & $(\mathrm{mg} / \mathrm{kg})$ & Média \pm E.P. & Inibição (\%) & Média \pm E.P. & Inibição (\%) \\
\hline Controle & - & $70,00 \pm 4,24$ & - & $116,12 \pm 2,23$ & - \\
& 100 & $61,25 \pm 7,52$ & 12,50 & $111,75 \pm 9,67$ & 3,76 \\
Extrato & 200 & $45,50 \pm 2,10^{*}$ & 35,00 & $115,12 \pm 2,34$ & 0,86 \\
& 400 & $20,88 \pm 0,95^{*}$ & 70,17 & $86,25 \pm 1,87^{*}$ & 25,72 \\
Morfina & 5 & $12,50 \pm 0,92^{*}$ & 82,14 & $12,62 \pm 1,12^{*}$ & 89,13 \\
\hline
\end{tabular}

Tabela 2. Efeitos do extrato metanólico de Echinodorus grandiflorus sobre o edema de pata induzido por carragenina $(\mathrm{n}=6)$. Indometacina $(10 \mathrm{mg} / \mathrm{kg})$ foi o fármaco de referência. *Significativo após análise de variância (ANOVA) seguido do teste de Student Newman-Keuls $(\mathrm{p}<0,05)$.

\begin{tabular}{lccc}
\hline Grupos Experimentais & Doses $(\mathrm{mg} / \mathrm{kg})$ & \multicolumn{2}{c}{ Volume do edema (mL) } \\
\cline { 3 - 4 } & & $0,90 \pm 0,04$ & Inibição (\%) \\
\hline Controle & - & $0,75 \pm 0,04^{*}$ & - \\
& $100 \mathrm{mg} / \mathrm{kg}$ & $0,57 \pm 0,03^{*}$ & 36,67 \\
Extrato & $200 \mathrm{mg} / \mathrm{kg}$ & $0,45 \pm 0,04^{*}$ & 50,00 \\
& $400 \mathrm{mg} / \mathrm{kg}$ & $0,40 \pm 0,03^{*}$ & 55,56 \\
\hline
\end{tabular}

Tabela 3. Efeitos do extrato metanólico de Echinodorus grandiflorus sobre o volume do exsudato da pleurisia induzida por carragenina $(n=6)$. Indometacina $(10 \mathrm{mg} / \mathrm{kg})$ foi o fármaco de referência. *Significativo após análise de variância (ANOVA) seguido do teste de Student Newman-Keuls $(\mathrm{p}<0,05)$.

\begin{tabular}{lccc}
\hline Grupos Experimentais & Doses $(\mathrm{mg} / \mathrm{kg})$ & \multicolumn{2}{c}{ Volume do exsudato (mL) } \\
\cline { 3 - 4 } & & $1,95 \pm 0,04$ & Inibição (\%) \\
\hline Controle & - & $1,80 \pm 0,07$ & - \\
& $100 \mathrm{mg} / \mathrm{kg}$ & $1,77 \pm 0,07$ & 9,23 \\
Extrato & $200 \mathrm{mg} / \mathrm{kg}$ & $1,47 \pm 0,06^{*}$ & 24,61 \\
& $400 \mathrm{mg} / \mathrm{kg}$ & $1,17 \pm 0,09^{*}$ & 40,00 \\
\hline
\end{tabular}

Tabela 4. Efeitos do extrato metanólico de Echinodorus grandiflorus sobre o $\mathrm{n}^{\mathrm{o}}$ de leucócitos totais do exsudato da pleurisia induzida por carragenina $(\mathrm{n}=6)$. Indometacina $(10 \mathrm{mg} / \mathrm{kg})$ foi o fármaco de referência. *Significativo após análise de variância (ANOVA) seguido do teste de Student Newman-Keuls $(\mathrm{p}<0,05)$.

\begin{tabular}{|c|c|c|c|c|}
\hline \multirow[t]{2}{*}{ Grupos Experimentais } & \multirow[t]{2}{*}{ Doses (mg/kg) } & \multicolumn{2}{|c|}{ Leucócitos Totais $\times 10^{3} / \mathrm{mm}^{3}$} & \\
\hline & & Média \pm E.P. & Inibição (\%) & \\
\hline \multirow[t]{2}{*}{ Controle } & - & $25,52 \pm 0,25$ & - & \\
\hline & $100 \mathrm{mg} / \mathrm{kg}$ & $25,18 \pm 0,26$ & 1,33 & \\
\hline \multirow[t]{2}{*}{ Extrato } & $200 \mathrm{mg} / \mathrm{kg}$ & $21,86 \pm 0,33 *$ & 14,34 & \\
\hline & $400 \mathrm{mg} / \mathrm{kg}$ & $19,68 \pm 0,22 *$ & 22,88 & \\
\hline \multirow[t]{2}{*}{ Indometacina } & $10 \mathrm{mg} / \mathrm{kg}$ & $12,14 \pm 0,22 *$ & 52,43 & \\
\hline & & & $\begin{array}{r}\text { Rev. Bras. Farmacogn. } \\
\text { Braz J. Pharmacogn. } \\
\text { 16(4):out/dez. } 2006\end{array}$ & 471 \\
\hline
\end{tabular}


$\mathrm{mL} / \mathrm{kg}$ de dimetilsufóxido:Tween 80 (1:1) 1\% em salina por via oral. Morfina $(5 \mathrm{mg} / \mathrm{kg}$, subcutânea) foi usada como fármaco de referência.

\section{Avaliação da atividade antiinflamatória}

\section{Teste do edema de pata induzido por carragenina em ratos}

O edema de pata foi induzido pela injeção de $0,1 \mathrm{~mL}$ de carragenina $(1 \% \mathrm{p} / \mathrm{v})$ em salina estéril e administrada na região subplantar da pata direita de rato Wistar machos $(n=6)$. Uma hora antes da injeção de carragenina, o extrato metanólico de E. grandiflorus, solubilizado em dimetilsulfóxido:Tween 80 (1:1) $1 \%$ $(\mathrm{v} / \mathrm{v})$ em salina, foi administrado, por via oral, nas doses de 100, 200 e $400 \mathrm{mg} / \mathrm{kg}$ (Winter et al., 1962). O grupo controle recebeu $10 \mathrm{~mL} / \mathrm{kg}$ de dimetilsufóxido:Tween 80 (1:1) $1 \%$ em salina por via oral. Na pata esquerda, usada como controle, foi injetada $0,1 \mathrm{~mL}$ de salina estéril. Após quatro horas de injeção de carragenina, a medida do edema foi feita pela diferença entre o volume deslocado da pata direita e o volume deslocado da pata esquerda. Indometacina $(10 \mathrm{mg} / \mathrm{kg}$, v.o.) foi usada como fármaco de referência.

\section{Teste da pleurisia induzida por carragenina em ratos}

A pleurisia foi induzida em ratos Wistar pela injeção intrapleural de $0,5 \mathrm{~mL}$, entre a terceira e a quinta costela do lado direito do mediastino, de uma suspensão de carragenina 1\% em solução salina estéril (Vinegar et al., 1973). Grupos de seis ratos foram tratados com extrato metanólico (solubilizado em dimetilsulfóxido: tween $80(1: 1) 1 \%(\mathrm{v} / \mathrm{v})$ em salina) de E. grandiflorus $(100,200$ e $400 \mathrm{mg} / \mathrm{kg})$, indometacina ( $10 \mathrm{mg} / \mathrm{kg}$, v.o.) ou salina $(10 \mathrm{~mL} / \mathrm{kg})$ uma hora antes da aplicação do agente inflamatório. Quatro horas após a indução da inflamação, os animais foram anestesiados com uma solução de cloridrato de cetamina $(75 \mathrm{mg} / \mathrm{kg}$ ) e cloridrato de xilazina $(10 \mathrm{mg} / \mathrm{kg})$ e sacrificados. Uma incisão foi feita entre a terceira e quinta costela em cada lado do mediastino. $\mathrm{O}$ exsudato pleural foi coletado, transferido a um tubo cônico de centrífuga e o volume foi determinado. Uma alíquota de $50 \mu \mathrm{L}$ do exsudato foi usada para determinar a contagem total de leucócitos em câmara de Neubauer. Realizou-se também a contagem de polimorfonucleares e mononucleares em esfregaços preparados em lâminas e corados com corante de Leishmann.

\section{Análise estatística}

Os resultados foram demonstrados através da média \pm erro padrão. Análise de variância (ANOVA) seguida do teste de Student Newman-Keuls foi utilizada para medir o grau de significância $(\mathrm{p}<0,05)$.

\section{RESULTADOS}

O efeito do extrato metanólico dos rizomas de E. grandiflorus demonstrou que as doses de 100, 200 e $400 \mathrm{mg} / \mathrm{kg}$ do extrato metanólico causou inibição das contorções abdominais em 34,30\%, 35,84\% e 36,07\%, respectivamente (Figura 1). A indometacina inibiu 75,22\% as contorções, mostrando sua eficácia como analgésico.

A injeção intraplantar de $2,5 \%$ de formalina promoveu uma resposta característica bifásica (Tabela 1). A duração do tempo de lambida na primeira fase (0-5 min) foi de 70,00 \pm 4,24 $\mathrm{s}$ e na segunda fase (15-30 $\mathrm{min}$ ) foi de $116,12 \pm 2,23 \mathrm{~s}$ para o grupo controle. Após 60 minutos de tratamento, as doses de 200 e $400 \mathrm{mg} / \mathrm{kg}$ inibiram a primeira fase do tempo de lambida em 35,00 e $70,17 \%$, respectivamente, enquanto a dose de $400 \mathrm{mg} / \mathrm{kg}$ reduziu a segunda fase em $25,72 \%(\mathrm{p}<0,05)$. Como esperado, a morfina $(5 \mathrm{mg} / \mathrm{kg})$ foi ativa em ambas as fases.

$\mathrm{O}$ efeito antiinflamatório do extrato metanólico de E. grandiflorus avaliado pelo o método do edema de pata induzido por carragenina é mostrado na Tabela 2. A inibição do edema foi observada nas doses de $100 \mathrm{mg} / \mathrm{kg}$ (16,67\%), $200 \mathrm{mg} / \mathrm{kg}(36,67 \%)$ e $400 \mathrm{mg} / \mathrm{kg}(50,00 \%)$ que reduziu em relação ao controle. Os efeitos sobre a pleurisia induzida por carragenina demonstraram que somente a dose de $400 \mathrm{mg} / \mathrm{kg}$ reduziu, significativamente $(\mathrm{p}<0,05)$, o volume do exsudato $(1,47 \pm 0,06,24,61 \%)$, embora a inibição da migração leucocitária foi significativa $(\mathrm{p}<0,05)$ nas doses de 200 e $400 \mathrm{mg} / \mathrm{kg}$ com $14,34 \%$ e $22,88 \%$, respectivamente (Tabelas 3 e 4 ). A indometacina $(10 \mathrm{mg} / \mathrm{kg})$ diminuiu o edema de pata, assim como o volume do exsudato e a migração leucocitária. Não houve diferença significativa entre polimorfonucleares e mononucleares em relação ao controle.

\section{DISCUSSÃO}

O estudo indicou que o extrato metanólico de E. grandiflorus possui propriedades analgésicas sobre o sistema nervoso periférico e central. A atividade analgésica periférica foi demonstrada pelos efeitos inibitórios das contorções abdominais e dos tempos de lambida da pata. Além da atividade antinociceptiva, o teste do tempo da lambida da pata também indicou uma possível atividade antiinflamatória (Figura 1 e Tabela 1).

Os modelos de nocicepção empregados envolvem diferentes mecanismos da dor, tais como o sistema simpático com liberação de aminas bioativas, os metabólitos da via do ácido araquidônico (Duarte et al., 1992) e o sistema opióide (Collier et al., 1968). O ácido acético age induzindo a liberação de mediadores endógenos que estimulam os nociceptores que são sensíveis aos antiinflamatórios não-esteróides e/ou opióides (Collier et al., 1968). A atividade do extrato metanólico de $E$. grandiflorus observada na $1^{\text {a }}$ fase do tempo da lambida da pata é típica de uma ação em nível de sistema nervoso central, como demonstrada pela morfina, 
embora esta possua efeitos em ambas as fases (Shibata et al., 1989). No entanto, a $2^{\mathrm{a}}$ fase é caracterizada pelo surgimento de um processo inflamatório local, onde são produzidos mediadores da inflamação. Esses mediadores são inibidos por fármacos antiinflamatórios tais como ácido acetilsalicílico, indometacina e dexametasona. Como o extrato produziu efeito significativo na $2^{\text {a }}$ fase, provavelmente, a diminuição do tempo da lambida da pata induzida pela formalina se deve à inibição da biossíntese de mediadores responsáveis pela inflamação, como por exemplo, inibição da ciclooxigenase e conseqüentemente das prostaglandinas (Farsam et al., 2000). Isso está de acordo com os resultados de contorções abdominais, pois a indometacina, antiinflamatório não-esteróide, foi utilizada como fármaco de referência.

Para confirmar a possível atividade antiinflamatória demonstrada do teste da formalina, o extrato metanólico de E. grandiflorus foi avaliado no modelo do edema da pata induzido por carragenina (Tabela 2). A carragenina, um agente inflamatório, produz inflamação por liberação de prostaglandinas, ocasionando a formação de um edema. Foi observado que a atividade antiedematogênica do extrato testado parece ser dependente da dose. É possível que, assim como a indometacina, componentes deste extrato estejam inibindo a biossíntese de prostaglandinas (Farsam et al., 2000).

Na pleurisia, injeção intrapleural de carragenina promove aumento do volume do exsudato na cavidade pleural (Ammendola et al., 1975; Almeida et al., 1980) e migração leucocitária (Compasso et al., 1975; Almeida et al., 1980), o que constitui um método importante para avaliar infiltrado inflamatório e confirmar a atividade antiinflamatória demonstrada através do edema de pata. Os antiinflamatórios não-esteróides, tal como a indometacina, inibem a acumulação do exsudato e mobilização de leucócito entre 3 e 6 horas após carragenina (Vinegar et al., 1973; Almeida et al., 1980). Os resultados demonstraram ação semelhante à da indometacina em 4 horas após aplicação da carragenina (Tabelas 3 e 4).

Portanto, o extrato metanólico de rizomas de $E$. grandiflorus possui componentes ativos com atividades antinociceptiva e antiinflamatória como demonstrado nos métodos empregados podendo constituir um potencial para fins terapêuticos.

\section{AGRADECIMENTOS}

Nossos agradecimentos ao CNPq e a UFJF pelas bolsas de iniciação científica. À Profa. Dra. Célia Hitomi Yamamoto pela correção do "Abstract".

\section{REFERÊNCIAS}

Almeida ALF, Pimenta DS, Figueiredo MR, Tibiriçá E 2003. Investigação dos mecanismos de ação envolvidos

no efeito vasodilatador de extrato bruto aquoso de Echinodorus grandiflorus em aorta isolada de coelho. XXXV Congresso Brasileiro de Farmacologia $e$ Terapêutica Experimental. Águas de Lindóia, Brasil.

Almeida AP, Bayer BM, Horakova Z, Beaven MA 1980. Influence of indomethacin and other anti-inflammatory drugs on mobilization and production of neutrophils: studies with carrageenan-induced inflammation in rats. J Pharmacol Exp Ther 214: 74-79.

Ammendola G, Di Rosa GM, Sorrentino L 1975. Leucocyte migration and lysosomal enzymes release in rat carrageenin pleurisy. Agents Actions 5: 250-255.

Barbosa-Filho JM, Vasconcelos THC, Alencar AA, Batista LM, Oliveira RAG, Guedes DN, Falcão HS, Moura MD, Diniz MFFM, Modesto-Filho J 2005. Plants and their active constituents from South, Central, and North America with hypoglycemic activity. Rev Bras Farmacogn 15: 392-413.

Brito FA, Sampaio ALF, Pimenta DS, Figueiredo MR, Kaplan MAC, Henriques MGMO 1999. Inibição por extratos de Echinodorus grandiflorus do edema de pata induzido pelo composto 48/80, histamina e serotonina. XIV Reunião Anual da Federação de Sociedades de Biologia Experimental. Caxambu, Brasil.

Collier HO, Dinneen LC, Johnson CA, Schneider C 1968. The abdominal constriction response and its suppression by analgesic drugs in the mouse. Br J Pharmacol Chemother 32: 295-310.

Compasso F, Dunn CJ, Yamamoto S, Willougbby DA, Giroud JP 1975. Further studies on carrageenan-induced pleurisy in rats. $J$ Pathol 116: 117-124.

Costa M, Tanaka CMA, Imamura PM, Marsaioli AJ 1999. Isolation and synthesis of a new clerodane from Echinodorus grandiflorus. Phytochemistry 50: 117122.

Duarte IDG, Ferreira-Alves DL, Nakamura-Craig M 1992. Possible participation of endogenous opioid peptides on the mechanism involved in analgesia by vouacapan. Life Sci 50: 891-897.

Farsam H, Amanlou M, Dehpour AR, Jahaniani F 2000. Antiinflammatory and analgesic activity of Biebersteinia multifida DC. root extract. J Ethnopharmacol 71: 443447.

Hunskaar S, Hole K 1987. The formalin test in mice: dissociation between inflammatory and non-inflammatory pain. Pain 30: 103-114.

Kobayashi J, Sekiguchi M, Shigemori H, Ohsaki A 2000. Echinophyllins A and B, novel nitrogen-containing clerodane diterpenoids from Echinodorus macrophyllus. Tetrahedron Lett 41: 2939-2943.

Koster R, Anderson M, Beer EJ 1959. Acetic acid for analgesic screening. Federation Proceedings 18: 412.

Lopes LC, Albano F, Laranja GAT, Alves LM, Silva LFM, Souza GP, Araújo IM, Nogueira-Neto JF, Felzenszwalb I, Kovary K 2000. Toxicological evaluation by in vitro and in vivo assays of an aqueous extract prepared from Echinodorus macrophyllus leaves. Toxicol Lett 116: 189-198.

Lorenzi H 2000. Plantas daninhas do Brasil: terrestres, aquáticas e tóxicas. Nova Odessa: Instituto Plantarum de Estudos da Flora Ltda.

Lorenzi H, Matos FJA 2002. Plantas medicinais no Brasil: nativas e exóticas cultivadas. Nova Odessa: Instituto 
Plantarum de Estudos da Flora Ltda.

Manns D, Hartmann R 1993. Echinodol: a new cembrene derivate from Echinodorus grandiflorus. Planta Med 59: 465-466.

Nunes GP, Silva MF, Resende UM, Siqueira JM 2003. Plantas medicinais comercializadas por raizeiros no Centro de Campo Grande, Mato Grosso do Sul. Rev Bras Farmacogn 13: 83-92.

Shibata M, Ohkubo T, Takahashi H, Inoki R 1989. Modified formalin test: characteristic biphasic pain response. Pain 38: 347-352.

Shigemori H, Shimamoto S, Sekiguchi M, Ohsaki A, Kobayashi J 2002. Echinodolides A and B, new cembrane diterpenoids with an eight-membered lactone ring from the leaves of Echinodorus macrophyllus. J Nat Prod 65: 82-84.

Tanaka CMA, Sarragiotto MH, Zukerman-Schpector J, Marsaioli AJ 1997. A cembrane from Echinodorus grandiflorus. Phytochemistry 44: 1547-1549.

Tanaka CMA 2000. Constituintes químicos de cinco espécies de Echinodorus e avaliação do $\beta$-pineno como substrato para obtenção de quírons mais elaborados. Campinas, 298p. Tese de Doutorado - Universidade Estadual de Campinas.

Vieira, MF, Lima, NAS 1997. Pollination of Echinodorus grandiflorus (Alismataceae). Aquat Botany, 58: 8998.

Vinegar R, Traux JF, Selph JL 1973. Some quantitative temporal characteristic of carrageenin-induced pleurisy in the rat. Proc Soc Exp Biol Med 143: 711-714.

Winter CA, Risley EA, Nuss GW 1962. Carrageenin-induced edema in hind paw of the rat as an assay for antiinflammatory drugs. Proc Soc Exp Biol Med 111: 544-547. 